\title{
Utility of Endoscopic Retrograde Cholangiopancreatography in Management of Pediatric Pancreaticobiliary Disease
}

\section{Satoshi Makita ( $\sim$ sat-mkt@med.nagoya-u.ac.jp )}

Nagoya University Graduate School of Medicine

Hizuru Amano

Nagoya University Graduate School of Medicine

Hiroki Kawashima

Nagoya University Graduate School of Medicine

Akinari Hinoki

Nagoya University Graduate School of Medicine

Chiyoe Shirota

Nagoya University Graduate School of Medicine

Takahisa Tainaka

Nagoya University Graduate School of Medicine

Wataru Sumida

Nagoya University Graduate School of Medicine

Kazuki Yokota

Nagoya University Graduate School of Medicine

Masamune Okamoto

Nagoya University Graduate School of Medicine

Aitaro Takimoto

Nagoya University Graduate School of Medicine

Akihiro Yasui

Nagoya University Graduate School of Medicine

\section{Yoichi Nakagawa}

Nagoya University Graduate School of Medicine

Hiroo Uchida

Nagoya University Graduate School of Medicine

\section{Research Article}

Keywords: endoscopic retrograde cholangiopancreatography, pancreatitis, congenital biliary dilatation, stent 
Posted Date: July 20th, 2021

DOl: https://doi.org/10.21203/rs.3.rs-707761/v1

License: (c) (1) This work is licensed under a Creative Commons Attribution 4.0 International License. Read Full License

Version of Record: A version of this preprint was published at BMC Pediatrics on March 14th, 2022. See the published version at https://doi.org/10.1186/s12887-022-03207-3. 


\section{Abstract}

Background: The purpose of this study was to evaluate the utility of endoscopic retrograde cholangiopancreatography (ERCP) in pediatric patients with pancreaticobiliary diseases.

Methods: A retrospective review was performed on patients who underwent ERCP for the treatment of biliary tract disease and detailed examination of pancreatitis at our institution from January 1999 to December 2020.

Results: ERCP was performed for congenital biliary dilatation $(n=42)$, choledocholithiasis $(n=9)$, common bile duct stenosis $(n=1)$, and several types of pancreatitis $(n=13)$. The only severe complication of ERCP was common bile duct injury. Three (5.8\%) of 52 biliary diseases failed to be treated by ERCP. All patients with pancreatic disease were correctly diagnosed and treated.

Conclusion: Endoscopic biliary drainage with a temporary stent was adequate for symptomatic relief. Stenting of the pancreatic duct was useful for improving the angulation and drainage of the pancreatic duct. ERCP was useful for understanding the anatomy of the pancreatic duct and revealing potential treatments. Therefore, ERCP and transendoscopic therapy are sufficiently feasible in pediatric patients and should be actively introduced for the investigation and treatment of pancreaticobiliary diseases.

\section{Introduction}

The use of diagnostic and therapeutic endoscopic retrograde cholangiopancreatography (ERCP) is steadily increasing in the management of pancreaticobiliary diseases in children [1]. While magnetic resonance cholangiopancreatography (MRCP) is one of the diagnostic imaging modalities available for detecting anatomical abnormalities, MRCP images cannot fully identify anatomical abnormalities in pediatric patients. Therefore, there is a need to identify the scope and utility of ERCP in children with pancreaticobiliary diseases.

We previously performed ERCP in asymptomatic patients with congenital biliary dilatation (CBD) to ascertain anatomical details [2, 3]. Of late, however, ERCP is performed only in symptomatic CBD patients for therapeutic purposes, so as to avoid associated complications.

In addition to CBD, ERCP is also performed for the treatment of choledocholithiasis and for the investigation and treatment of unexplained pancreatitis.

The etiologies of pediatric pancreatitis include drugs, infections, trauma, and anatomical abnormalities. In Japan, Suzuki et al. reviewed 145 pediatric patients with acute pancreatitis and reported that $54.5 \%$ of cases were caused by anatomical abnormalities [4]. For patients with unexplained pancreatitis, ERCP and endoscopic transpapillary therapy have been performed as required to detect anatomical abnormalities. The purpose of this study was to evaluate the utility of ERCP in pediatric patients with pancreaticobiliary diseases. 


\section{Patients And Methods}

A retrospective review was performed concerning patients who underwent ERCP for the treatment of biliary tract disease and detailed investigation of the cause of pancreatitis at our institution, from January 1999 to December 2020. Our current treatment strategy for preoperative management of CBD is shown in Fig. 1. The strategy for pancreatitis suspected to be caused by anatomical abnormalities is shown in Fig. 2. ERCP for symptomatic CBD was performed as early as the regular examination schedule permitted after referral to our institution, while ERCP for pancreatitis was scheduled once the clinical symptoms of pancreatitis improved; in both instances, the procedures was performed under general anesthesia. Pancreatitis was defined as the presence of abdominal pain with hyperamylasemia and inflammation. All endoscopic procedures were performed by trained gastroenterologists. For endoscopy, PJF-7.5 (tip outer diameter, $7.8 \mathrm{~mm}$; channel diameter, $2.0 \mathrm{~mm}$; Olympus) and JF-240 (tip outer diameter, $12.6 \mathrm{~mm}$; channel diameter, $3.2 \mathrm{~mm}$; Olympus) were used for infants and school-age children, respectively. The endoscope was selected depending on the body size of the patient and the procedure to be performed. PJF-7.5 was used only for contrast and stent tube insertion. We selected JF-240 for papillotomy since it allowed us to deliver various devices. Endoscopic pancreatic stenting (EPS) was performed for flexion, stenosis, and dilatation of the pancreatic duct to prevent pancreatitis. Endoscopic transpapillary therapy (stent tube insertion or papillotomy) was attempted when drainage of the bile duct or pancreatic duct drainage was deemed necessary.

This study was approved by the ethics committee of our institution (\#2020 - 0635). Informed consent from participants or their parents/guardians was obtained through an opt-out method on our hospital website in accordance with the Ethical Guidelines for Medical and Health Research Involving Human Subjects in Japan.

\section{Results}

Over the 22-year observation period, ERCP was performed in 52 patients for the treatment of biliary diseases, and in 13 patients for the examination and treatment of pancreatic diseases.

\section{Complications after ERCP}

Other than one 2-year-old patient with choledocholithiasis who temporarily required endoscopic nasobiliary tubing for common bile duct injury secondary to ERCP, no other complications, such as severe pancreatitis, bleeding, or perforation, were noted.

\section{ERCP treatment outcomes by disease}

\section{Biliary duct disease}

CBD 
The details of ERCP for CBD are shown in Table 1. Of 38 symptomatic patients, placement of a biliary stent tube before radical surgery was successful in 32 . All 32 patients who underwent stent insertion were relieved of their symptoms. Two patients were relieved of symptomatic pain and did not require stenting by removing the protein plug. Stenting in the other four patients was unsuccessful due to flexion or obstruction of the narrow segment of the biliary tract. Three of the four patients were relieved of their symptoms by means other than stenting. Two (a 5-month-old boy and a 6-month-old boy) of four patients underwent percutaneous transhepatic biliary drainage, and their symptoms improved thereafter. Repeated insertion of the guidewire crushed the protein plug in one patient (a 1-year-old girl), who was subsequently also relieved of her symptoms. The other patient (also a 1-year-old girl) continued to experience abdominal pain for 6 days until radical surgery.

Table 1

Details regarding ERCP for biliary duct disease.

\begin{tabular}{|ll|}
\hline Details regarding ERCP & $\mathbf{n}$ \\
\hline Congenital biliary dilatation (median age: 3.9 year-old [0.4-14.7 ]) & 42 \\
\hline Preoperative treatment & 32 \\
\hline Endoscopic biliary stent & 2 \\
\hline Removal of protein plug in the common channel & $4(2)$ \\
\hline Failure to insert stent (converted to percutaneous transhepatic biliary drainage) & \\
\hline Intraoperative treatment & 1 \\
\hline EPS for intraoperative pancreatic duct injury & 1 \\
\hline Pancreatography after pancreatic duct injury repair & 1 \\
\hline Postoperative treatment & 1 \\
\hline EPS for intraoperative pancreatic duct injury & 9 \\
\hline Removal of protein plug from the pancreatic duct & 9 \\
\hline Choledocholithiasis (median age: 6.6 years [ 0.3-10.2 ]) & 1 \\
\hline Endoscopic removal of stones by papillary balloon dilatation & 1 \\
\hline Common bile duct stenosis (age: 11.3 years) & \\
\hline Endoscopic balloon dilatation of common bile duct & \\
\hline ERCP, endoscopic retrograde cholangiopancreatography & \\
\hline EPS, endoscopic pancreatic stenting & \\
\hline
\end{tabular}

Choledocholithiasis and common bile duct stenosis 
Endoscopic removal of common bile duct stones was successfully performed in nine patients with choledocholithiasis. Balloon dilatation was performed for common bile duct stenosis and restenosis was not observed after the procedure.

\section{Pancreatic disease}

A total of 38 ERCP procedures were performed in 13 patients with pancreatic disease. The details of ERCP for each patient are presented in Table 2. 
Table 2

The details regarding ERCP for pancreatitis

\begin{tabular}{|c|c|c|c|c|c|c|}
\hline Case & Disease & Sex & $\begin{array}{l}\text { Age at } \\
\text { onset } \\
\text { (years) }\end{array}$ & $\begin{array}{l}\text { Age at } \\
\text { initial ERCP } \\
\text { (years) }\end{array}$ & $\begin{array}{l}\text { No. } \\
\text { of } \\
\text { ERPs }\end{array}$ & Details regarding ERCP \\
\hline \multirow[t]{3}{*}{1} & \multirow{3}{*}{$\begin{array}{l}\text { Pancreatitis after } \\
\text { duodenal stenosis } \\
\text { surgery }\end{array}$} & \multirow[t]{3}{*}{$\mathrm{F}$} & \multirow[t]{3}{*}{2.8} & \multirow[t]{3}{*}{3.1} & \multirow[t]{3}{*}{3} & Contrast imaging - 1 \\
\hline & & & & & & $\begin{array}{l}\text { Papillary balloon } \\
\text { dilatation + remove } \\
\text { stone + EPS } 1\end{array}$ \\
\hline & & & & & & $\begin{array}{l}\text { Papillary balloon } \\
\text { dilatation + remove } \\
\text { stone } 1\end{array}$ \\
\hline \multirow[t]{3}{*}{2} & \multirow{3}{*}{$\begin{array}{l}\text { Pancreatitis after } \\
\text { duodenal atresia } \\
\text { surgery }\end{array}$} & \multirow[t]{3}{*}{$\mathrm{F}$} & \multirow[t]{3}{*}{6.5} & \multirow[t]{3}{*}{7.5} & \multirow[t]{3}{*}{6} & Contrast imaging 2 \\
\hline & & & & & & $\begin{array}{l}\text { Papillary balloon } \\
\text { dilatation + EPS } 1\end{array}$ \\
\hline & & & & & & EPS 3 \\
\hline \multirow[t]{2}{*}{3} & \multirow{2}{*}{$\begin{array}{l}\text { Pancreatitis after } \\
\text { duodenal atresia } \\
\text { surgery }\end{array}$} & \multirow[t]{2}{*}{$\mathrm{F}$} & \multirow[t]{2}{*}{1.8} & \multirow[t]{2}{*}{1.8} & \multirow[t]{2}{*}{5} & Contrast imaging 1 \\
\hline & & & & & & EPS 4 \\
\hline 4 & $\begin{array}{l}\text { Pancreatitis after } \\
\text { duodenal atresia } \\
\text { surgery }\end{array}$ & $M$ & 1.7 & 1.8 & 1 & Contrast imaging 1 \\
\hline \multirow[t]{3}{*}{5} & \multirow[t]{3}{*}{ Chronic pancreatitis } & \multirow[t]{3}{*}{$\mathrm{F}$} & \multirow[t]{3}{*}{2.4} & \multirow[t]{3}{*}{3.9} & \multirow[t]{3}{*}{6} & Contrast imaging 2 \\
\hline & & & & & & Removal of stone 1 \\
\hline & & & & & & EPS 3 \\
\hline \multirow[t]{3}{*}{6} & \multirow[t]{3}{*}{ Chronic pancreatitis } & \multirow[t]{3}{*}{$M$} & \multirow[t]{3}{*}{8} & \multirow[t]{3}{*}{12} & \multirow[t]{3}{*}{6} & Contrast imaging 1 \\
\hline & & & & & & Removal of stone 1 \\
\hline & & & & & & EPS 4 \\
\hline \multirow[t]{2}{*}{7} & \multirow[t]{2}{*}{ Chronic pancreatitis } & \multirow[t]{2}{*}{ M } & \multirow[t]{2}{*}{8} & \multirow[t]{2}{*}{8.3} & 3 & Contrast imaging 2 \\
\hline & & & & & & EPS 1 \\
\hline 8 & Pancreas divisum & $\mathrm{F}$ & 4.5 & 5.2 & 1 & Contrast imaging 1 \\
\hline 9 & Pancreas divisum & $\mathrm{F}$ & 5.1 & 5.8 & 2 & EPS 1 \\
\hline & & & & & & Minor papillotomy 1 \\
\hline
\end{tabular}

ERCP, endoscopic retrograde cholangiopancreatography;

EPS, endoscopic pancreatic stenting 


\begin{tabular}{|lllllll|}
\hline Case & Disease & Sex & $\begin{array}{l}\text { Age at } \\
\text { onset } \\
\text { (years) }\end{array}$ & $\begin{array}{l}\text { Age at } \\
\text { initial ERCP } \\
\text { (years) }\end{array}$ & $\begin{array}{l}\text { No. } \\
\text { of } \\
\text { ERPs }\end{array}$ & Details regarding ERCP \\
\hline 10 & $\begin{array}{l}\text { Autoimmune } \\
\text { pancreatitis }\end{array}$ & F & 12.4 & 12.6 & 2 & $\begin{array}{l}\text { Contrast imaging } 1 \\
\text { Bile duct stenting } 1\end{array}$ \\
\hline 11 & $\begin{array}{l}\text { Hereditary } \\
\text { pancreatitis }\end{array}$ & F & 5 & 8.7 & 1 & Contrast imaging 1 \\
\hline 12 & $\begin{array}{l}\text { Recurrent pancreatitis } \\
13\end{array}$ & M & 13 & 13.8 & 1 & Contrast imaging 1 \\
\hline ERCP, endoscopic retrograde cholangiopancreatography; & & 1 & Contrast imaging 1 \\
\hline EPS, endoscopic pancreatic stenting & & & & \\
\hline
\end{tabular}

In four patients with pancreatitis after congenital duodenal atresia/stenosis surgery, it was difficult to identify the main papilla during the ERCP. In two patients who underwent accessory papilla imaging, the accessory papilla was regarded as the main papilla during ERCP, and contrast imaging was performed. Three of the four patients had an annular pancreas (Figs. 3 and 4), and it was difficult to visualize the path of the pancreatic duct, even with contrast imaging. In Cases 1 and 3 , the path of the pancreatic duct could only be detected on repeated ERCPs.

All three patients with chronic pancreatitis had diffuse dilatation and wide irregularities involving the pancreatic duct, and pancreatic duct stents were emplaced. EPS was performed repeatedly; however, all patients eventually underwent pancreatic stent removal and were followed up without recurrence of pancreatitis (Fig. 5).

Of two patients with pancreas divisum, it was difficult to insert a stent into the accessory papilla in Case 8 and only contrast imaging was performed; the patient is currently being followed-up on an outpatient basis. In Case 9, stent placement into the accessory papilla and endoscopic minor papilla sphinctectomy was performed, as presented in Fig. 5.

In one patient with autoimmune pancreatitis, two ERCP procedures were performed. At the time of initial diagnosis, stenosis of the bile duct and pancreatic duct was found and a biliary stent was placed. Subsequently, steroidal therapy improved the stenosis, the stent was removed, and confirmatory contrast imaging was performed.

Three patients with hereditary pancreatitis and recurrent pancreatitis were found to have no anatomical abnormalities of the pancreatic duct on contrast imaging and were followed up in the pediatrics department.

\section{Discussion}


ERCP appears to be technically difficult and challenging in children because of their narrow airways and smaller anatomical dimensions compared to adults [5]. Improved designs of endoscopes and associated accessories have facilitated the development of ERCP procedures in children [1]. We found that diagnostic and therapeutic ERCP procedures could be successfully performed at three months of age. The only severe complication noted after ERCP was common bile duct injury; there were no cases of severe pancreatitis, bleeding, or perforation.

Endoscopic biliary drainage with a temporary stent is adequate for symptomatic relief of CBD. We previously reported that endoscopic short-tube stenting is beneficial in children because it does not require tube management [3]. In our present study, ERCP for biliary tract disease was highly successful and effective. Three (5.8\%) of the 52 biliary disease cases failed to be treated by ERCP owing to difficulties encountered in cannulation, when the narrow segment was right-angled, or the body size of the patient was too small for the procedure. Percutaneous transhepatic biliary drainage may be useful when stent tube placement is unsuccessful. It is not necessary to perform ERCP in all symptomatic CBD patients, as symptoms may improve with fasting alone. Our current treatment strategy for preoperative management of CBD (Fig. 1) is very effective in carefully selecting patients for ERCP and avoiding complications of ERCP.

In this study, patients who underwent ERCP for determination of the cause of and treatment for pediatric pancreatitis were also evaluated. ERCP was useful for understanding pancreatic duct anatomy. MRCP can reportedly be evaluated in the same way as ERCP [6]; however, in our experience, the images were unclear and difficult to evaluate. ERCP evaluation in children should be strongly considered because minor artifacts, as seen on MRCP, make evaluation difficult.

We reported four cases of pancreatitis after congenital duodenal atresia/stenosis surgery. Duodenal atresia and stenosis are often accompanied by pancreaticobiliary anomalies due to developmental reasons [7-9]. Growth may also lead to impaired pancreatic drainage due to ductal angulation. Detailed examination of pancreatitis after duodenal atresia associated with an annular pancreas can lead to the diagnoses of pancreaticobiliary maljunction, pancreas divisum, and CBD requiring surgical treatment in some patients [7-9]. Since a wide variety of anatomical abnormalities have been observed, there is a need to carefully search for underlying causes and to develop treatment strategies for pancreatitis after congenital duodenal atresia/stenosis surgery. In Case 2, a pancreatic duct stent was emplaced because the Wirsung duct was bent, and in Case 3, a pancreatic duct stent was placed in the dominant dorsal duct from the accessory papilla. These results suggested that stenting of the pancreatic duct should be useful for improving the angulation and drainage of the pancreatic duct.

In our study, EPS for chronic pancreatitis improved the stenosis that had caused acute exacerbations and, eventually, patients were followed up after repeated stenting without recurrence of pancreatitis. Endoscopic treatments for chronic pancreatitis have been reported to be effective, and favorable results have recently been reported with EPS $[5,10]$. EPS can be performed safely even in pediatric patients, and is often the first choice for endoscopic treatment. 
In addition, the indications for endoscopic minor papilla sphincterotomy can be decided by placing a pancreatic duct stent in patients with pancreatic divisum and setting the follow-up period. Endoscopic minor papilla sphincterotomy encompasses risk for certain complications such as perforation, bleeding, and acute pancreatitis, and incomplete incision may result in scar stenosis and impaired drainage [11]. Since there is no evidence recommending the direction and extent of the incision, the policy adopted at our institution is to consider minor papillotomy in patients aged 2 years or older (the JF-240 body size that allows the endoscope to be inserted). Thus, the indications for papillotomy should be carefully considered. These experiences suggest that our diagnosis and treatment strategies for pancreatitis in children (Fig. 2) are effective.

In conclusion, ERCP and transendoscopic therapy are sufficiently feasible in pediatric patients and should be actively introduced for the investigation and treatment of pancreaticobiliary diseases.

\section{Declarations}

\section{Ethics approval and consent to participate}

This study protocol was approved by Nagoya University Hospital Institutional review board (\#20200635). Because this was a retrospective observational study and the data analyzed were anonymized, informed consent from participants or their parents/guardians was obtained through an opt-out method on our hospital website in accordance with the Ethical Guidelines for Medical and Health Research Involving Human Subjects in Japan.

\section{Consent for publication}

Informed consent for publication was obtained in the form of opt-out.

\section{Availability of data and materials}

The datasets generated and/or analyzed during the current study are available from the corresponding author on reasonable request.

\section{Competing interests}

The authors declare that they have no competing interest.

\section{Funding}

None.

\section{Authors' contribution}

SM and HU designed this study. SM acquired data. HK performed all endoscopic procedures. SM, AH, CS, TT, WS, KY, MO, AT, AY and YN analyzed data. SM , HA and HU drafted the manuscript. All authors reviewed the manuscript and have given final approval of the version to be published.

\section{Acknowledgements}

Not applicable. 
Authors' information

Not applicable.

\section{References}

1. Hsu RK, Draganov P, Leung JW, Tarnasky PR, Andy SY, Hawes RH, et al. Therapeutic ERCP in the management of pancreatitis in children. Gastrointest Endosc. 2000;51:396-400.

2. Hiramatsu T, Itoh A, Kawashima H, Ohno E, Itoh Y, Sugimoto H, et al. Usefulness and safety of endoscopic retrograde cholangiopancreatography in children with pancreaticobiliary maljunction. $J$ Pediatr Surg. 2015;50:377-81.

3. Tsuchiya H, Kaneko K, Itoh A, Kawashima H, Ono Y, Tainaka T, et al. Endoscopic biliary drainage for children with persistent or exacerbated symptoms of choledochal cyst. J Hepatobiliary Pancreat Sci. 2013;20:303-6.

4. Suzuki M, Saito N, Naritaka N, Nakano S, Minowa K, Honda Y, et al. Scoring system for the prediction of severe acute pancreatitis in children. Pediatr Int. 2015;57:113-8.

5. Agarwal J, Nageshwar Reddy D, Talukdar R, Lakhtakia S, Ramchandani M, Tandan M, et al. ERCP in the management of pancreatic diseases in children. Gastrointest Endosc. 2013;79:271-8.

6. Fumino S, Ono S, Kimura O, Deguchi E, Iwai N. Diagnostic impact of computed tomography cholangiography and magnetic resonance cholangiopancreatogpraphy on pancreaticobiliary maljunction. J Pediatr Surg. 2011;46:1373-8.

7. Ando H, Kaneko K, Ito F, Seo T, Harada T, Watanabe Y. Embryogenesis of pancreaticobiliary maljunction inferred from development of duodenal atresia. J Hepatobiliary Pancreat Sug. 1999;6:50-4.

8. Urushihara N, Fukumoto K, Fukuzawa H, Suzuki K, Matsuoka T, Kawashima S, et al. Recurrent pancreatitis caused by pancreatobiliary anomalies in children with annular pancreas. J Pediatr Surg. 2010;45:741-6.

9. Sato N, Shimura T, Kenjo A, Kimura T, Watanabe J, Muto M, et al. Pancreaticobiliary maljunction diagnosed long after laparotomy in the neonatal period for annular pancreas: report of a case. Surg Case Rep. 2019;5:16.

10. Oracz G, Pertkiewicz J, Kierkus J, Dadalski M, Socha J, Ryzko J. Efficiency of pancreatic duct stenting therapy in children with chronic pancreatitis. Gastrointest Endosc. 2014;80:1022-9.

11. Cho JM, Jeong IS, Kim HJ. Early adverse events and long-term outcomes of endoscopic sphincterotomy in a pediatric population: a single-center experience. Endoscopy. 2017;49:438-46. 


\section{Figures}

\section{Congenital biliary dilatation}

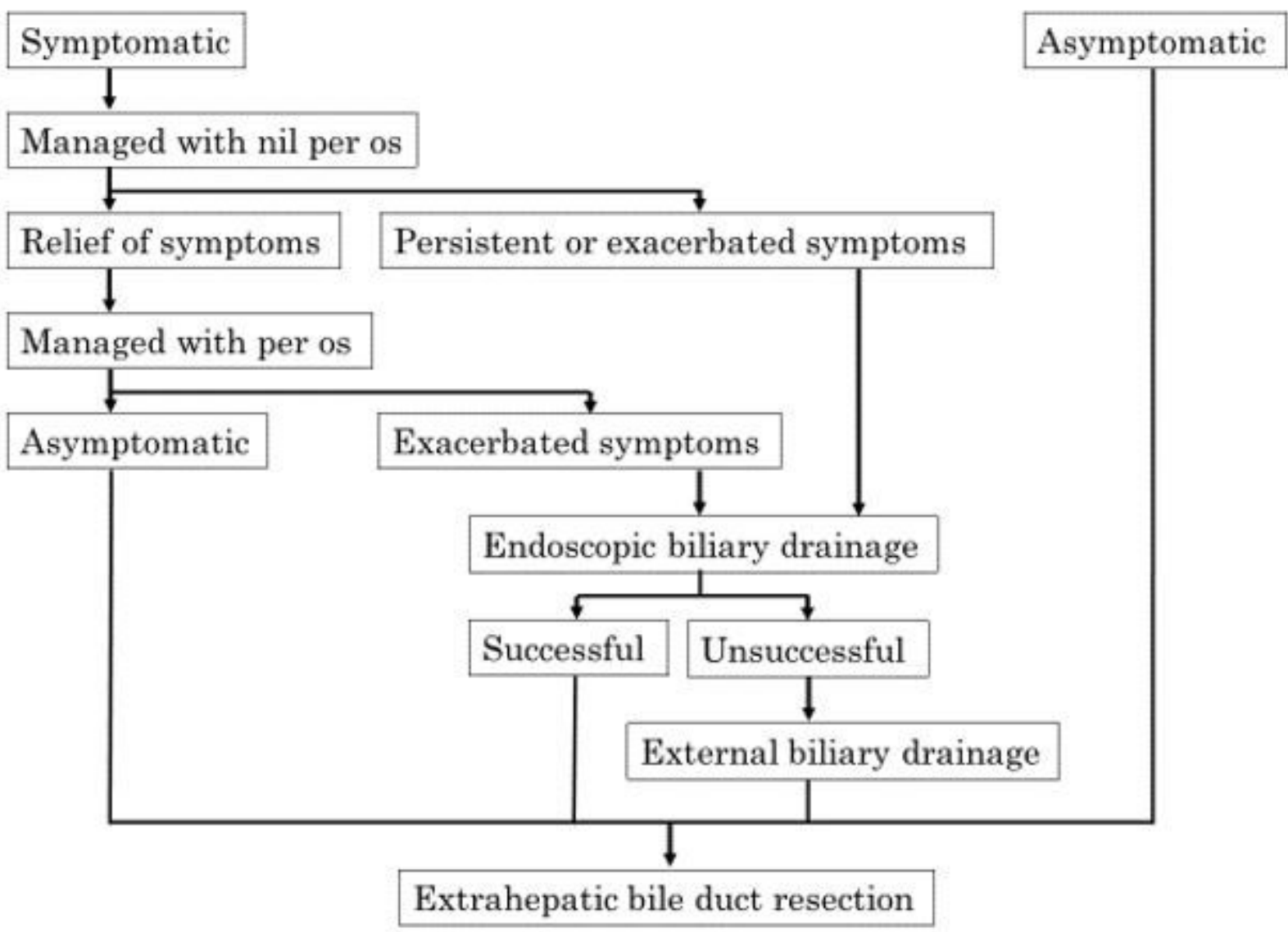

\section{Figure 1}

Treatment strategy for preoperative management of congenital biliary dilatation in children 


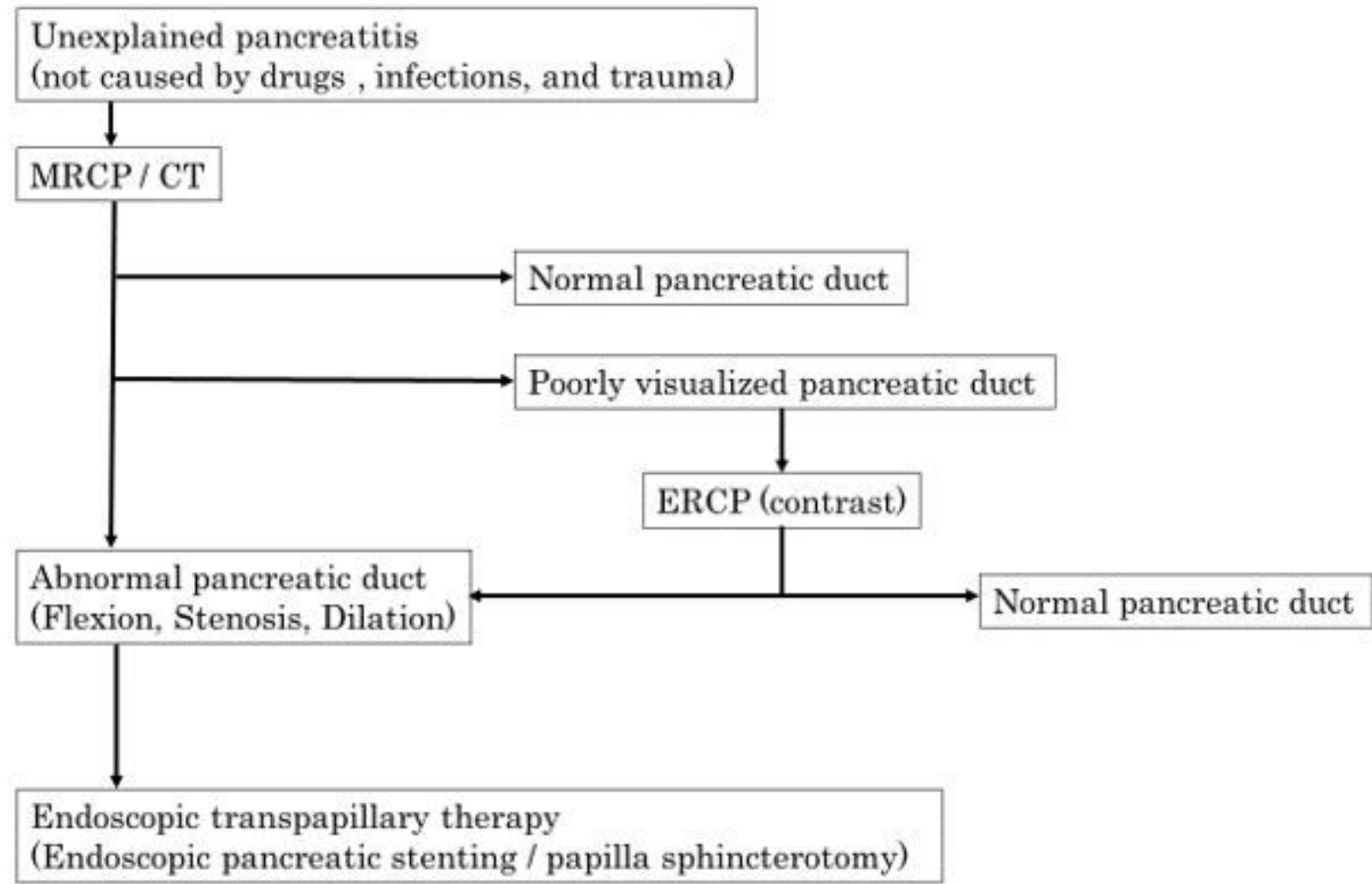

Figure 2

Strategy for investigation of recurrent pancreatitis in children 

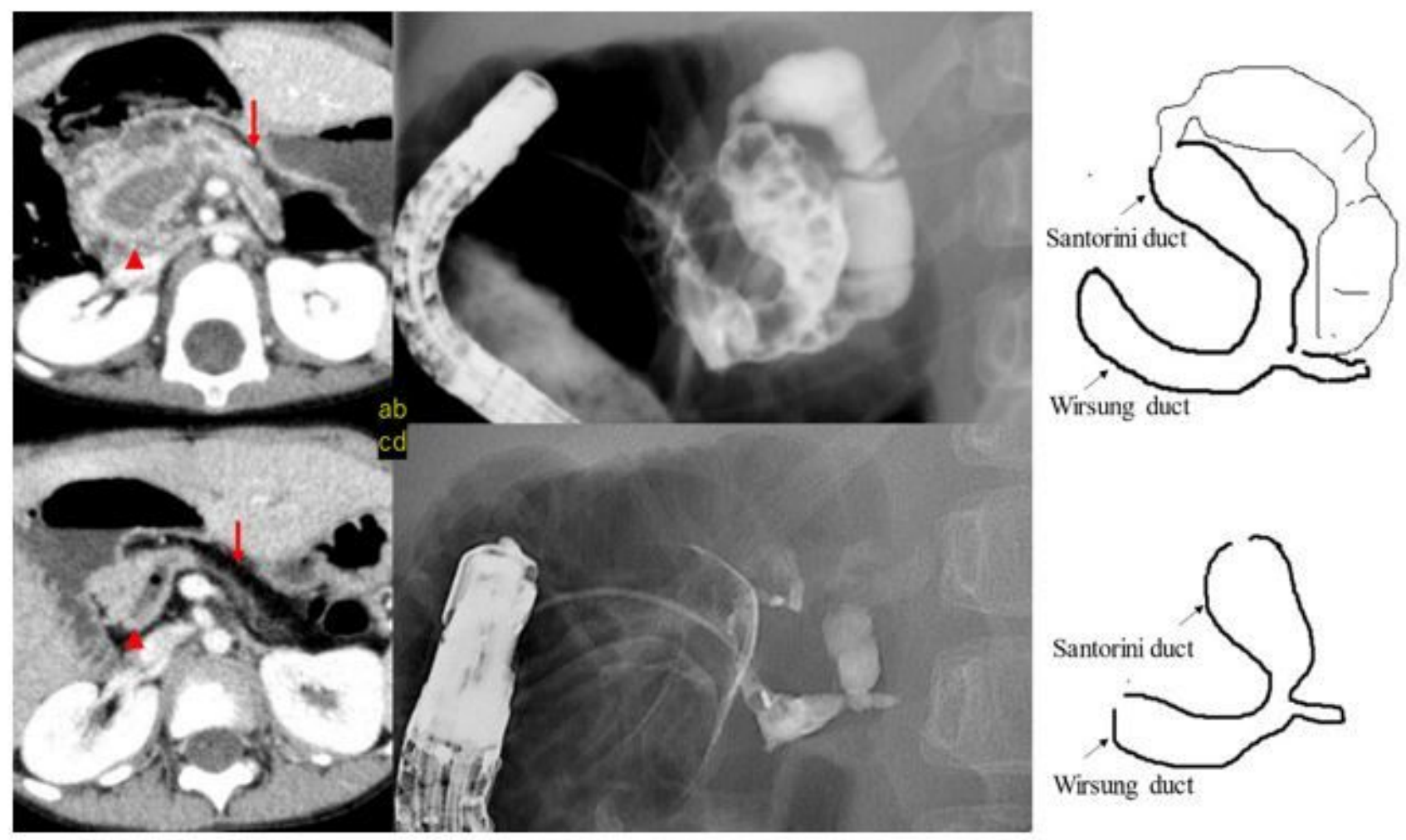

Wirsung duct

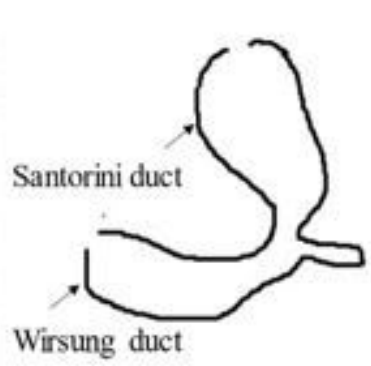

\section{Figure 3}

Case 1. Computed tomography (CT) and endoscopic retrograde cholangiopancreatography (ECRP) images of a 3.1-year-old patient are shown in (a) and (b). Pancreatic stones were found in the pancreatic head, and the pancreatic duct was dilated. CT and ERCP images at 6.3 years of age are shown in (c) and (d). Atrophy of the tail of the pancreas and decreased exocrine function were also observed. Several ERCP attempts were in vain; thereafter, Frey's procedure was performed at 7-years of age, and there has been no occurrence of pancreatitis since. Arrowhead: pancreatic head, pancreatic duct; Arrow: pancreatic tail 

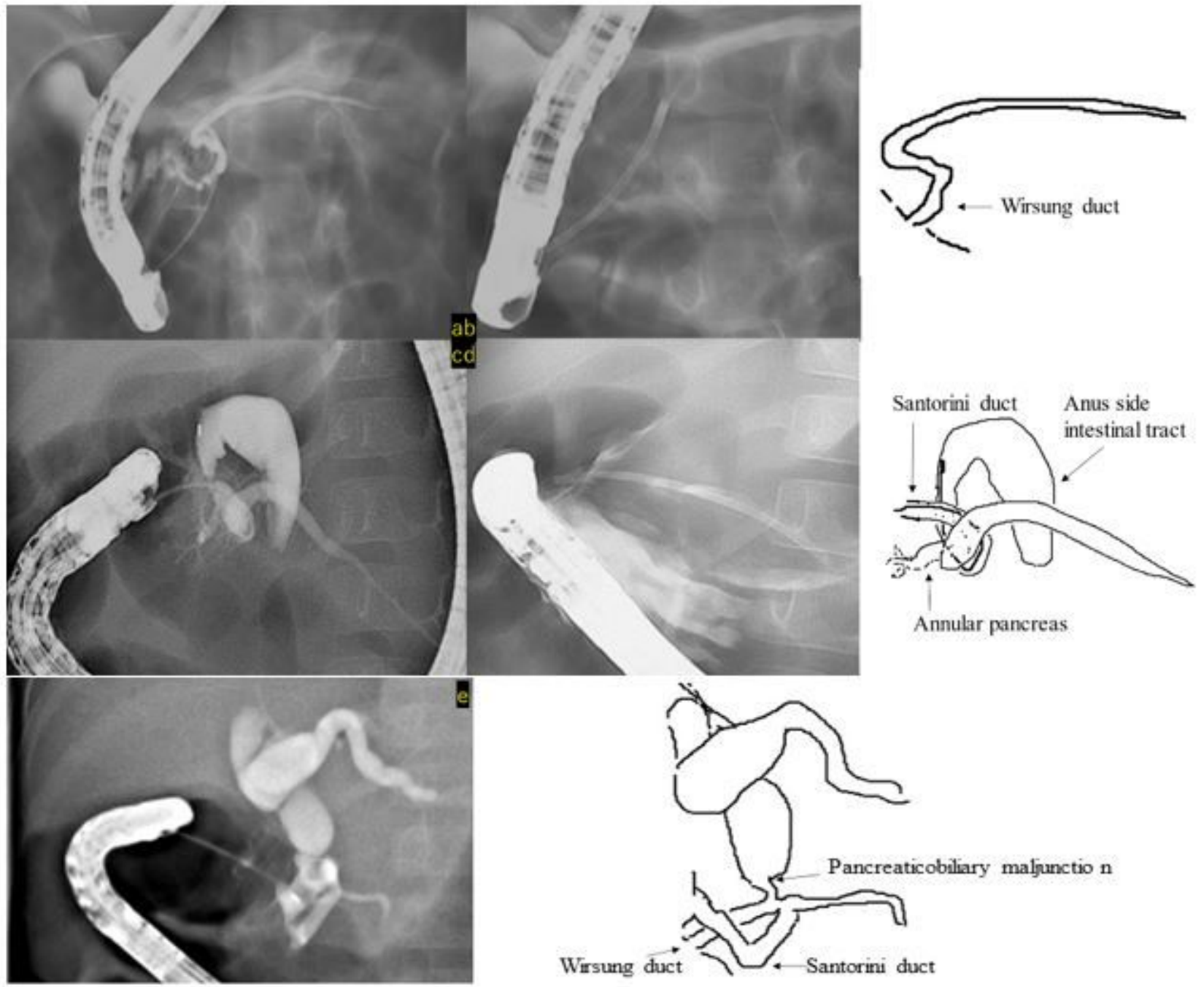

(1)

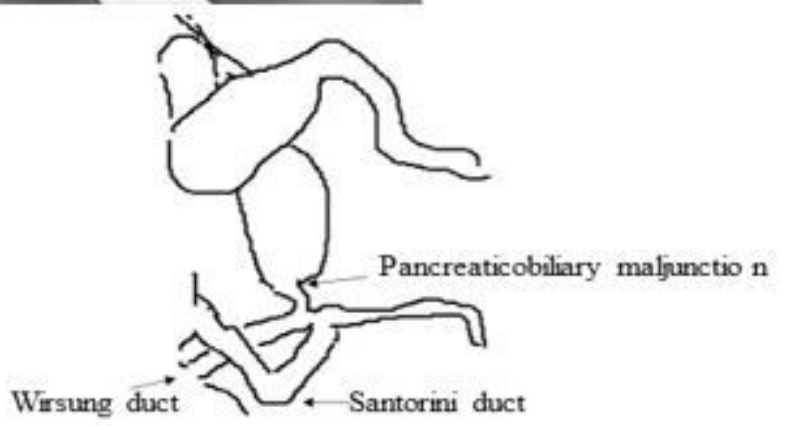

\section{Figure 4}

$(a, b)$ : Case 2 - Pancreatic duct stent insertion into the caudal pancreatic duct from the main papilla, for flexion of the Wirsung duct and removal of pancreatic stone. Removal of the stent resulted in recurrence of symptoms; thus, the pancreatic duct stent was replaced regularly and the patient was followed-up. Recurrence of symptoms was not observed for 13 months after stent placement. (c, d): Case 3 - Contrastenhanced imaging of the accessory papilla: insertion of a pancreatic duct stent into the caudal pancreatic duct. During the initial endoscopic retrograde cholangiopancreatography, the stent could not be inserted into the main papilla. After repeated occurrence of pancreatitis, a dominant dorsal duct was diagnosed. The patient required regular stent replacement, and was free from pancreatitis for 19 months after initial stent placement. (e): Case 4 - Contrast-enhanced imaging of the accessory papilla: angulation of the Santorini duct, pancreaticobiliary maljunction, and dilatation of the common bile duct seen in a 1year-old. The patient was diagnosed with congenital biliary dilatation and underwent laparoscopic radical surgery at the age of 1 year and 10 months. He had no pancreatitis for 4 years. 


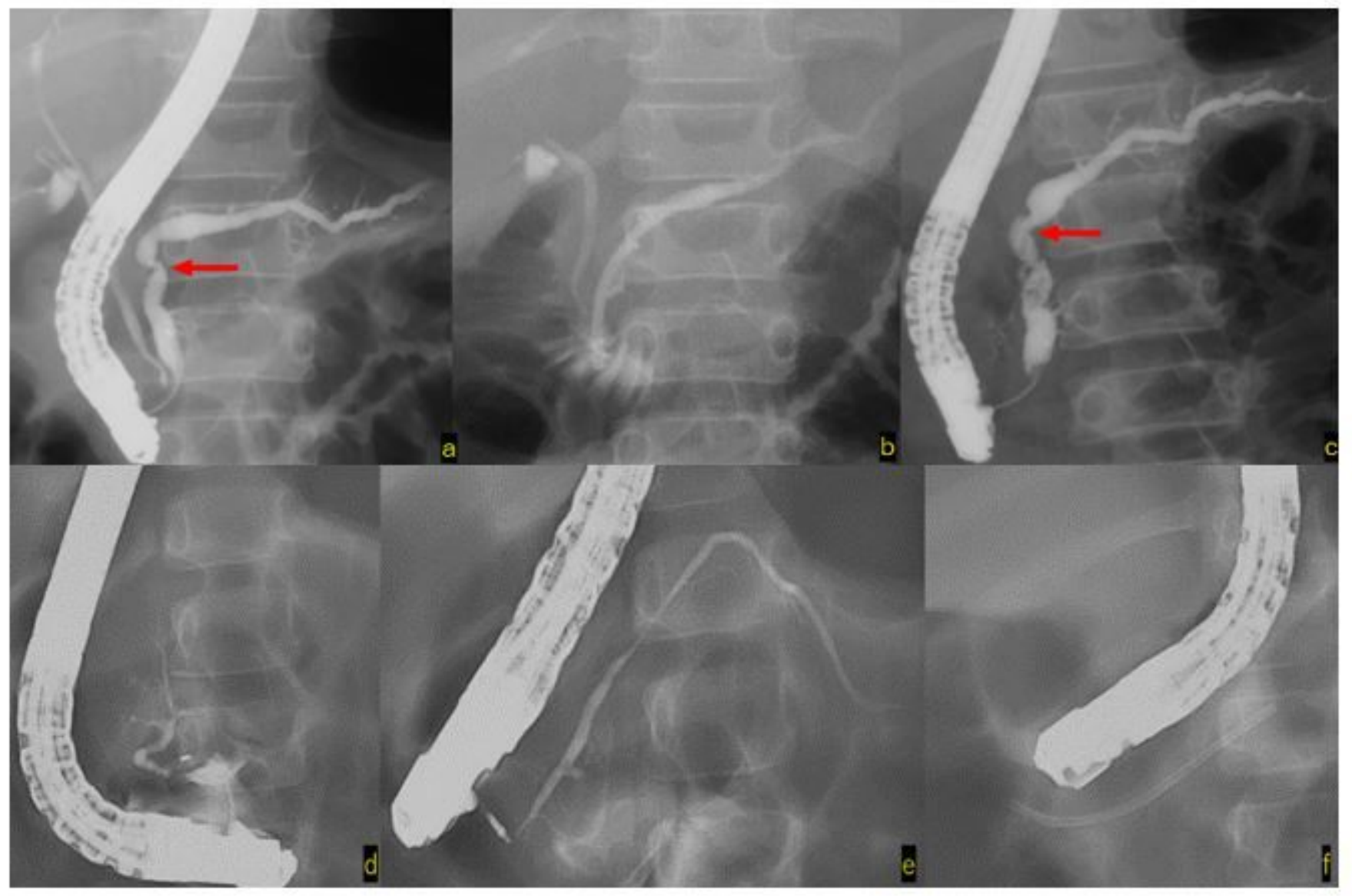

Figure 5

Case $5(a, b)$ : At the time of the initial endoscopic retrograde cholangiopancreatography, stenosis was found in the main pancreatic duct, as seen in the figure. Pancreatic duct stent placement was performed. (c): Improvement of stenosis observed at the time of pancreatic duct stent removal. No recurrence of pancreatitis was observed for 14 years and 5 months after stent removal. Case 9 (d) Contrast imaging of the main papilla shows disruption of the Wirsung duct (e) Contrast imaging of the caudal pancreatic duct through contrast imaging of the accessory papilla (f) Stent placement from the accessory papilla to the caudal pancreatic duct Endoscopic minor papilla sphincterotomy was performed, and no recurrence of pancreatitis was observed for 15 months. 